\title{
O NEXO DE CAUSALIDADE NA RESPONSABILIDADE TRANSFRONTEIRIÇA EM RELAÇÃO À PROTEÇÃO HÍDRICA NA SOCIEDADE DE RISCO ${ }^{1}$
}

\author{
Tiago da Rosa Sena Silveira
}

Resumo: A preocupante escassez da água para consumo aliada às constantes poluições transfronteiriças dos recursos hídricos têm provocado fervoroso debate entre as autoridades mundiais. Entre os temas discute-se a responsabilização de Estados e indivíduos na poluição de bens hídricos. Sob a perspectiva da atual sociedade de risco em que vivemos, teoria idealizada por Ulrich Beck, propõe-se uma nova forma de encarar a responsabilidade internacional por poluição hídrica transfronteiriça: a inversão do dever de provar o nexo de causalidade, devendo o empreendedor demonstrar que a atividade exercida não acarreta riscos ou danos ambientais eventuais e futuros.

Palavras-chave: Responsabilidade transfronteiriça. Sociedade de risco. Nexo de causalidade.

1 Artigo científico elaborado sob a orientação da profa . me. Elizete Lanzoni Alves.

2 Bacharel em Direito pela Universidade do Sul de Santa Catarina - UNISUL. Pós-graduado em Direito Ambiental pelo Grupo Educacional Uninter e pós-graduando em Direito Público pela Escola Superior da Magistratura Estadual de Santa Catarina - ESMESC. Juiz leigo e técnico judiciário do Tribunal de Justiça de Santa Catarina. E-mail: tiagosilveirajuridico@gmail.com. 


\section{INTRODUÇÃO}

A escassez de água tem sido tema de grandes desafios enfrentados pela civilização. É notório que a água constitui elemento vital para os seres vivos e que se produz senão por meio naturalístico. Hoje o problema toma contornos mais críticos. De acordo com a Unesco em relatório divulgado no $3^{\circ}$ Fórum Mundial da Água realizado em 2003, estima-se que, na pior das hipóteses, 7 bilhões de pessoas em 60 países estarão enfrentando falta de água na metade deste século. Na melhor das hipóteses, serão 2 bilhões de pessoas em 48 países nesta situação.

Somada à superpopulação atual, o avançado estágio atual do desenvolvimento econômico-industrial (característico da sociedade pós-moderna) tem evidenciado a insegurança nas relações humanas, sobretudo as jurídicas, tendo em vista a multiplicação de riscos gerados pela proliferação de inovações tecnológicas. Se na era moderna tinha-se a concepção de absoluta previsão sobre os riscos gerados pelas atividades, ante a crença de que a ciência poderia antecipar os resultados e erradicar as incertezas, hoje surge a ideia diametralmente oposta. Imagina-se assim a hipótese de imprevisibilidade dos riscos advindos pelo exercício das mesmas atividades, no presente e no futuro, vindo a inserir a sociedade numa constante vertente de riscos, ou, segundo a concepção de Ulrich Beck, remodelando-a em uma “sociedade de risco" (BECK, 2010).

Mira-se a atenção à realidade das águas e os efeitos jurígenos produzidos a partir de impactos transfronteiriços, em sua amplitude global, perfeitamente justificável dada a imprescindibilidade deste "microbem ambiental" 3 à subsistência de todas as formas de vida no universo. Assim este artigo procura engajar a tutela dos recursos hídricos no contexto de uma sociedade de riscos proposta por Beck, cujo aporte teórico conduz à interpre-

\footnotetext{
3 Termo utilizado por José Rubens Morato Leite e Patrick de Araújo Ayala em sua obra "Dano ambiental: do individual ao coletivo extrapatrimonial", cuja referência completa pode ser visualizada ao final deste trabalho.
} 
tação sobre o elemento do nexo causal, requisito do instituto da responsabilidade civil, sob a modalidade objetiva, em contraposição à clássica responsabilidade subjetiva ou aquiliana.

Entre os inúmeros entraves à responsabilização ambiental, em especial relacionado com a reparação hídrica, está a dificuldade de comprovação do nexo de causalidade, cujo componente da responsabilidade civil será dedicado um capítulo exclusivo. A complexa tarefa de demonstrar o enlace existente entre a atividade exercida e o dano ambiental emergente (ou de um possível dano) conduz a necessidade de inverter a obrigação natural de prova. Dessa forma ao empreendedor compete, antes de exercer sua atividade ou quando constatada a ocorrência de um afetamento ao bem ambiental, esclarecer que sua atividade não contribui ou contribuiu com o prejuízo, conforme o caso. Se antes era dever do lesionado provar suas alegações, cabe agora ao empreendedor desvencilhar-se de responsabilidade que a si é atraída em razão do risco da atividade exercida.

Baseado em pesquisa de fonte bibliográfica constituída de obras especializadas no assunto, bem como informações retiradas de pesquisa eletrônica da internet, o artigo terá, em seu primeiro capítulo, a abordagem acerca do Direito Ambiental visto sob a perspectiva da sociedade de risco, sendo conceituados a própria disciplina de Direito Ambiental, meio ambiente e princípios inspiradores do ramo jurídico, fechando o capítulo com a contextualização do tema sociedade de risco.

No segundo capítulo dar-se-á a incursão sobre a responsabilidade ambiental internacional e a poluição transfronteiriça hídrica, cujos assuntos remetem às responsabilidades internacionais de cunho subjetiva e objetiva dispostas nos tratados. Serão mencionados também alguns mecanismos jurídicos colocados à disposição da Corte Internacional na resolução de conflitos que envolvem a referida poluição transfronteiriça das águas.

Como anunciado a pouco, no terceiro capítulo analisar-se-á o nexo de causalidade inerente à responsabilidade sobre a proteção hídrica transfronteiriça, apontando a atual predo- 
minância de responsabilidade regulamentadora dos diplomas internacionais.

Longe de esgotar o assunto e de apontar a medida mais adequada, propõem-se mostrar a possibilidade de utilização do instituto da inversão do ônus da prova ambiental como meio catalizador à efetividade da responsabilidade ambiental internacional em assuntos relacionados à tutela das águas.

\section{DIREITO AMBIENTAL NA SOCIEDADE DE RISCO}

O Brasil, baseado no modelo português-romano do civil law, assiste à edição de uma avalancha de normas jurídicas superiores ao de costume, em especial concernente à matéria ambiental. A necessidade de tantas leis, sem levar em consideração a característica própria do modelo herdado, é fruto de uma série de fatos motivada pelo "desenvolvimento econômico-tecnológico-industrial-cultural” e seus desdobramentos. Existe a concepção por parte da sociedade de que a lei regulamentadora possa garantir, além da paz social, a incolumidade sobre o bem juridicamente tutelado. Na ótica de Ulrich Beck (2010) a partir do cenário retratado é criado o que ele denomina de “irresponsabilidade organizada”. Significa dizer que a própria regulação, a quem competiria, em tese, responsabilizar os infratores, passa a legitimar estes por vias indiretas. Ou seja, perdura uma lógica de descontrole institucionalizada, de forma que o sistema ocupa-se com pequenos riscos tecnicamente manejáveis e, por outro lado, ignora os grandes riscos a ponto de torná-los legítimos ante a falta de atuação estatal. Dentro desse contexto que o presente capítulo busca tratar o direito ambiental.

\subsection{Conceito de meio ambiente}

Interessante definição pode ser encontrada na Lei n. 6.938/81, pela qual meio ambiente é "o conjunto de condições, leis, influências e interações de ordem física, química e 
biológica, que permite, abriga e rege a vida em todas as suas formas" (art. $\left.3^{\circ}, \mathrm{I}\right)$. Por relacionar um termo com extensa amplitude considerou-se que o meio ambiente pode ser entendido em dois campos de análise: o incorpóreo e o material. Assim Leite (2003, p. 91) considera o meio ambiente como um macrobem unitário e integrado ecologicamente equilibrado, incorpóreo e imaterial, de uso comum do povo.

Noutro vértice o meio ambiente é observado como microbem, ou seja, como bens materiais individualizados (LEITE, 2003, p. 85). Nos termos da preceituada lei são os recursos ambientais, constituídos pela atmosfera, os estuários, o mar territorial, o solo, o subsolo, os elementos da biosfera, a fauna, a flora e, inclusive, as águas interiores, superficiais e subterrâneas (art. $\left.3^{\circ}, \mathrm{V}\right)$.

Em nível internacional a própria definição de "meio ambiente" fazia pressupor a imprescindibilidade de uma regulamentação em nível global. $\mathrm{O}$ meio ambiente, dado seu aspecto físico e natural uno, espanca quaisquer obstáculos fronteiriços, criados pelo comportamento humano, o que evidencia a primazia do estudo sobre meio ambiente em seu teor holístico. Vale dizer que os estudos ambientais não se limitam a espaços locais, estanques, mas, sobretudo em espaços globais que desconhecem compartimentos de cunho político-territorial. Após certa resistência pela comunidade internacional foi editada uma definição sobre o termo em foco, consagrada na Convenção Europeia sobre Responsabilidade Civil por Danos Resultantes de Atividades Prejudiciais ao Meio Ambiente: "meio ambiente inclui: recursos naturais, seja abióticos seja bióticos, como o ar, a água, o solo, a fauna e a flora, e a interação entre tais fatores; propriedades que formam parte da herança cultural; e os aspectos característicos da paisagem" (art. $\left.2^{\circ}, \S 10\right)$ (SOARES, 2001, p. 24). A seguir considerações sobre o direito ambiental. 


\subsection{Conceito de direito ambiental}

Para Milaré (2001, p. 109) a disciplina do Direito Ambiental pode ser entendida como o conjunto de princípios e normas reguladoras das atividades humanas que afetam o equilíbrio do ambiente em sua amplitude global, para fins de resguardar a sustentabilidade do espaço para as presentes e futuras gerações.

Destaca-se o rigor multidisciplinar próprio do ramo, cujos conhecimentos, para a Ciência Jurídica, resgatam, entre outras disciplinas, institutos do Direito Internacional Público, Constitucional, Penal, Civil, Processual Civil e Administrativo. Outras ciências estão relacionadas ao aprofundamento do Direito Ambiental, tais como a Biologia e Engenharia Florestal.

Em relação à Economia, diante da crise atual que vem enfrentando as forças de produção mundiais, não se pode olvidar a relevante influência do meio ambiente sobre a economia. Apesar de as grandes potências reconhecerem o meio ambiente como variável à ciência econômica, elas acabam priorizando as pesquisas em torno de outras variáveis, o que enfraquece a importância do ambiente em assuntos econômicos, muito embora a prudência recomende o contrário. Se for certo que a superpopulação mundial e o aumento exacerbado do consumo, fruto do modelo capitalista em vigor, constitui, a primeira evidência, as causas da crise, por outro lado insere-se o problema da escassez dos recursos naturais, cuja análise faz-se de forma escamoteada. Seja o petróleo, a água ou os minérios essenciais à produção industrial é evidente que o esgotamento das fontes naturais tem sido um dos principais motivos pela quebra-quebra das principais potências, entre elas os EUA e a União Europeia. O Direito Ambiental faz promover a reflexão sobre o papel do homem no mundo e como ele encara e utiliza os elementos que o cerca. Se no passado o modo de viver estava baseado numa visão antropocêntrica pura (o homem como centro do universo), hoje se exige uma atenuação desta em favor das demais formas de vida. É a forma de relativizar a concepção antropocêntrica que ganhou forte impulso a partir da era renascentista da civilização (idade 
moderna). $\mathrm{O}$ que se pretende levar em conta então é a soma de outros componentes - o meio ambiente - como centro das atenções junto com o próprio homem, o que não desconfigura este como principal objeto de estudo.

Dessarte advoga-se a superação do antropocentrismo pretérito e a inclusão de novos valores na proteção jurídica do meio ambiente. Trata-se da inauguração da bioética, conectada com o direito e que pode ser entendida como ramo do saber ético que se ocupa da discussão e conservação de valores morais de respeito à pessoa humana no campo das ciências da vida (LIMA, 1997, p. 46).

Se não bastasse, o êxito da gestão patrimonial está atrelado a necessária equidade intergeracional ${ }^{4}$, concebida como a obrigação de cada geração levar à seguinte um nível de qualidade ambiental igual ou superior ao que recebeu da geração anterior.

\subsection{Princípios específicos do direito ambiental - precaução, prevenção, poluidor-pagador, solidariedade e cooperação}

O caráter elementar dos princípios para o Direito redimensiona o primeiro à posição nuclear do sistema. A qualidade fundamental dos princípios despeja sua influência sobre as demais normas, a ponto de afirmar o conhecimento dos mesmos princípios é condição sine qua non para aplicação do Direito em sua inteireza.

\subsubsection{Princípio da prevenção e da precaução}

Para situar o leitor cumpre registrar que parcela significativa da doutrina destaca pequenas diferenças entre os princípios intitulados. Assim o princípio da prevenção exige que apenas os perigos comprovados sejam excluídos, enquanto no princípio da

\footnotetext{
4 Expressão usada pelos Patryck de Araújo Ayala e José Rubens Morato Leite na obra intitulada "Direito ambiental na sociedade de risco", cuja referência completa encontra-se disponível em lista de referência deste artigo.
} 
precaução determina que todos os possíveis impactos danosos sejam eliminados antes mesmo da averiguação do nexo causal e de sua evidência científica absoluta (Aragão 1997, p. 68).

Adotamos, contudo, o posicionamento de Fiorillo (2009, p. 54) que considera despicienda a diferenciação. Trata-se de alimentar discussão doutrinária de efeito prático nulo, cuja diferença serve apenas para fins pedagógico e histórico.

Entre outros textos legais, a Lei n. 9.605/98 consubstancia tais princípios em seu art. 54, quando prevê o delito de poluição (caput) e equipara o infrator às mesmas sanções se não forem tomadas as medidas de precaução em caso de risco de dano ambiental grave ou irreversível $\left(\S 3^{\circ}\right)$.

Interessante notar que o princípio da precaução/prevenção coaduna-se com o não menos importante princípio da consciência ecológica, que sustenta o dever de todos na conservação dos recursos naturais disponíveis. Não obstante a falta de menção direta não resta a menor dúvida de que a previsão constitucional do Estudo do Impacto Ambiental - EIA representa a prescrição normativa e a materialização do princípio. Dispõe o art. 225 que "todos têm direito ao meio ambiente ecologicamente equilibrado" (caput), cabendo ao Poder Público exigir estudo prévio de impacto ambiental para instalação de obra ou atividade potencialmente causadora de significativa degradação (inc. IV).

Em âmbito internacional não se pode deixar de apontar o disposto na Declaração do Rio de Janeiro de 1992, norteador do axioma no ordenamento brasileiro. Enfatiza o princípio n. 15 a obrigação de os Estados observarem amplamente o princípio, conforme suas capacidades. Alerta ainda o dispositivo a imprescindibilidade da medida preventiva, de forma que a ausência de absoluta certeza científica não deverá ser utilizada como razão para postergar medidas eficazes e economicamente viáveis para prevenir a degradação ambiental.

Tal princípio possui uma peculiaridade ímpar que o remete a uma conotação larga dentro da concepção ambiental e para 
além de seu tempo atual. Não só os danos emergentes devem ser respaldados pela lei, mas também aqueles projetados para o futuro. Isso porque a efetividade do princípio tem por objeto não só a sociedade presente, mas também as futuras gerações. Daí a importância da compreensão dos danos futuros, tendo em vista o direito das futuras gerações ao ambiente equilibrado (equidade intergeracional).

Dessarte os danos futuros estão divididos em danos futuros estrito senso, progressivo e potencial: (a) o primeiro diz respeito a um dano certo, porém ainda não concretizado no momento da elaboração da perícia sobre o local impactado. (b) $O$ segundo advém da ação cumulativa das atividades de vários agentes pela qual resta impossível a determinação da procedência. (c) $\mathrm{O}$ último provém do reconhecimento dos efeitos não conhecidos, mas apenas prováveis que por si só possibilitariam imputar, senão a responsabilidade, mas ao menos o ônus da prova do autor de eventual prejuízo (SILVA, 2006, p. 216).

Curioso observar que o princípio ambiental quebra o paradigma clássico da responsabilidade civil, este manifestado apenas após a lesão a bem jurídico tutelado. Dadas as circunstâncias à preservação do meio ambiente vê-se o aperfeiçoamento do próprio Direito quando se procura antever uma possível lesão a um bem jurídico, instituto que poderá servir de modelo a outras áreas jurídicas.

\subsubsection{Princípio do usuário-poluidor-pagador}

Tal preceito representa não apenas a concretude da responsabilidade ambiental, como também o fundamento que possibilita responder, em tese, ao problema das externalidades decorrentes das atividades produtivas. Ensina a doutrina que externalidades correspondem aos efeitos causados pela produção de um certo agente, em que os primeiros afetam diretamente interesses de terceiros, sem a devida contraprestação (BESSA, 2000, 214). 
Conhecido ainda como princípio do usuário-pagador, este possui transcrição normativo-constitucional expressa no ordenamento pátrio e em declaração internacional do ambiente assim ementadas:

Princípio 16. As autoridades nacionais devem se esforçar para garantir a internacionalização dos custos da proteção ambiental e o uso de instrumentos econômicos, levando em conta que o poluidor deve, em princípio, arcar com os custos da poluição provocada; e com observância dos interesses públicos, sem perturbar o comércio e o investimento internacionais. (Inserido na Declaração.do Rio-92)

Art. 225 [...]

$\S 3^{\circ}$ As condutas e atividades consideradas lesivas ao meio ambiente sujeitarão os infratores, pessoas físicas ou jurídicas, a sanções penais e administrativas, independentemente da obrigação de reparar os danos causados. (Dispositivo previsto na CF)

Apercebe-se que o princípio acomete o empresário o dever de suportar os custos da atividade poluidora, bem como assumir total responsabilidade por quaisquer eventuais danos derivados. Se os lucros advindos da exploração dos recursos ambientais são destinados exclusivamente ao poluente, a ele as externalidades deverão ser direcionadas. Imaginar que estas sejam arcadas pela sociedade incorreria em odioso enriquecimento sem causa em prejuízo à própria coletividade em proveito de uma minoria.

Hupffer e Naime (2011, p. 10) revelam a fraca eficácia do mandamento ante a atual época de risco ambiental, como propõe Beck. Diante da irresponsabilidade organizada e legitimada, por vias indiretas, pela multiplicação de leis, o princípio do poluidor-pagador é esvaziado na prática, o que não retira sua importância desde que compreendido efetivamente os riscos da atividade poluidora e a necessidade de gerenciamento dos perigos, conhecidos ou desconhecidos: 
É nesse contexto que Beck insere a idéia de uma "irresponsabilidade organizada" que os riscos e perigos possuem, pois além de uma explosividade física eles possuem uma explosividade social. Sua análise teórica sobre "sociedade de risco global" o credencia a alertar a humanidade em relação aos danos ambientais sem limite, globais e irreparáveis, onde a noção de compensação (princípio do poluidor-pagador) fracassa. A mudança climática pode ser considerada o marco do novo paradigma da "irresponsabilidade organizada" resultado da soberania do mercado que nas palavras do autor representam uma ameaça mortal.

Seria descomedido perceber o princípio somente sob a ótica da sociedade de risco, de modo a ignorar outros contextos e conjunturas. Não obstante, dispensar a análise do mesmo princípio sem a atenção do risco aos mecanismos de preservação do meio fuminaria o seu próprio sentido ontológico.

\subsubsection{Princípios da cooperação e solidariedade}

Antes de servir como alicerce fundante específico do direito ambiental internacional, o princípio da cooperação compõe o conjunto de peculiaridades inerentes às relações entre Estados soberanos. Daí porque a CF de 1988 ressalvar tal princípio entre os outros que regem a República Federativa do Brasil nas suas relações internacionais, consignando a cooperação entre os povos para o progresso da humanidade (art. $4^{\circ}$, IX). Apesar de não haver menção direta, é possível deduzir que o espírito cooperativo está inserido entre os objetivos fundamentais da república, qual seja a erradicação da pobreza, marginalização e redução das desigualdades sociais e regionais (art. $3^{\circ}$, III). O princípio da cooperação significa então um trabalho em cadeia entre as nações com o fim único de preservação do meio ambiente, que desconhece fronteiras. Em nível internacional 
bastam lembrar as inúmeras referências da intenção cooperativa entre os Estados gizadas na Declaração do Rio, registrados nos preâmbulo, princípios n. 5, 7, 9, 12 etc.

O princípio da solidariedade, por sua vez, guarda estreita relação com a prefalada equidade intergeracional e os direitos daí decorrentes. Tal princípio clama pela construção de um novo paradigma comportamental, de modo a primar a importância dos valores ético-ambientais e coletivos em substituição do paradigma clássico, composto pela individuação de atores sociais e satisfação de necessidades essencialmente privadas.

Com o princípio da solidariedade não se pode dizer o direito "de todos" em sua inteireza, pois tal raciocínio resvala nos interesses de poucos, interessados tão-só na barganha pela atividade exercida, o que os descredencia, por óbvio, do coletivo "todos". Nesse sentido entendemos que o princípio merece uma interpretação complementar, encarada como prerrogativa sobrepujante aos interesses econômicos privativos, este de reduzido alcance. Pretende-se com isso superar a visão individualista, peculiar à perspectiva ocidental-liberal e implementar o uso da hermenêutica diatópica referida por Santos (1997, p. 11-32), cujas matizes priorizam a coexistência de elementos de coletivação e integração do bem ambiental. (fonte referida)

\subsection{Sociedade de risco: uma realidade que não pode ser desprezada}

$\mathrm{O}$ avanço das atividades humanas, elevado em escala exponencial ao passar dos anos, tem acarretado danos ambientais de ordem atemporal, cujos efeitos nem sempre são revelados imediatamente. ${ }^{5}$ Vale citar o progresso das pesquisas genéticas ou os desastres nucleares, em que não se tem a medida certa de suas consequências danosas. $\mathrm{O}$ risco provocado passa a consti-

\footnotetext{
5 Remete-se o leitor à leitura do item 1.3.1, do qual se extrai a possibilidade de os danos prolongarem ao longo do tempo, o que faz exsurgir a importância na aplicação dos princípios da precaução/prevenção em sua inteireza.
} 
tuir uma realidade que não pode ser mais desprezada pela sociedade.

Não obstante pensar que o ambiente está à mercê de constantes e intermináveis riscos, cujos danos materializados, em prejuízo da sociedade, estão encobertos pela pulverização de agentes poluidores, invisíveis e anônimos, entender a sociedade sobre esse contexto significa muito mais que a prática de denuncismo de efeitos meramente retóricos.

A compreensão da sociedade inserida no sistema de riscos e sustentada pelo modelo de consumo capitalista privatista é o ponto de partida para que se atenda aos objetivos de proteção do ambiente. Imperioso que as decisões sobre os problemas sejam tomadas a partir de uma correta percepção do risco.

De Giorgi (1994), importante estudioso sobre a influência do risco nas sociedades contemporâneas, pensa que a nova compreensão sobre o risco, ora inserido no contexto de insegurança e incerteza de acontecimentos posteriores, leva em conta as diferentes formas de representar o futuro a partir de um padrão ou medium. Segundo o autor o medium constitui um parâmetro para não só representar o futuro como também para produzir vínculos com o futuro. Se em época passada tinha-se a noção de que as formas de representação com o futuro (ou risco) dirigiam-se a uma finalidade objetiva, cujo resultado era possível calcular previamente, com a perspectiva de uma sociedade de risco tem-se que a representação com o futuro baseia-se na expectativa do provável. "O medium no qual o risco possibilita a construção de outras formas é o medium probalidade/ improbabilidade".

O mesmo autor acrescenta que o objetivo do medium não se restringe à identificação de beneficiários, como costuma suceder na atual sociedade de irresponsabilidade organizada. Mira-se afinal a distribuição de prejuízos pela constatação do incerto.

A leitura do modelo dá-se sobre o paradigma do incerto, do qual se extrai um mínimo de cálculo e previsão sobre efeitos 
provocados pelo risco da atividade, em projeção ao futuro. Imagina-se que o medium tenha como embasamento as ideias daquilo que se acha suportável e tolerável.

A consagração da sociedade de risco não esconde o temor pela alta dose de subjetivismo enquanto parte formadora do Estado de Direito Ambiental. Teme-se que o fato de inexistir precisos dados sobre os efeitos futuros provocados pela atividade possa arraigar conclusões hipotéticas manipuladas pelo subjetivismo nefasto. Daí a importância de estudos aprofundados e sólidos sobre os riscos das atividades, mesmo que, paradoxalmente, tenham-se como norte a incerteza dos efeitos gerados pela atividade.

\section{RESPONSABILIDADE AMBIENTAL E POLUIÇÃO HÍDRICA TRANSFRONTEIRIÇA}

A questão do impacto e responsabilidade ambiental relaciona-se diretamente com a poluição. Para fins de ilustração merece menção o sentido legal sobre poluição previsto na legislação brasileira que trata da Política Nacional do Meio Ambiente (Lei n. 6.838/80). Em sentido lato, a poluição advém da degradação da qualidade ambiental resultante de atividades que direta ou indiretamente: a) prejudiquem a saúde, a segurança e o bem-estar da população; b) criem condições adversas às atividades sociais e econômicas; c) afetem desfavoravelmente a biota; d) afetem as condições estéticas ou sanitárias do meio ambiente; e) lancem matérias ou energia em desacordo com os padrões ambientais estabelecidos (art. $3^{\circ}$, III). Para a extinta Secretaria do meio Ambiente do Brasil, regulada pelo Decreto n. 73.030/1973 poluição das águas significava "qualquer alteração de suas propriedades físicas, químicas ou biológicas, que possa importar em prejuízo à saúde, à segurança e ao bem-estar das populações, causar dano à flora e à fauna, ou comprometer o seu uso para fins sociais e econômicos" (art. 13, §1\%). Tais 
definições reputam-se necessária para inicialização do assunto deste capítulo que será abordado abaixo.

\subsection{Responsabilidade transfronteiriça internacional}

Estudar o instituto responsabilidade transfronteiriça é estudar, antes de tudo, parte específica do ramo do Direito Internacional, em especial a responsabilidade internacional. No entender de Charles Rousseau responsabilidade internacional é "um instituto jurídico, em virtude do qual, ao Estado a quem se imputa um ato ilícito segundo o Direito Internacional, deve reparação ao Estado em relação ao qual tal ato foi cometido" (tradução livre, apud SOARES, 2001, p. 712).

Diferentemente do que ocorre em âmbito nacional, a obrigação de reparar é dirigida somente aos Estados. A responsabilidade destes é inclusive indireta quando perpetrados atos ofensivos por indivíduos, situados em seu território, que não detêm o poder de representar a nação.

Acredita-se que a relação de dependência de significados entre os termos "águas transfronteiriças" e "impacto transfronteiriço" ocorra da mesma forma que há entre a expressões "responsabilidade ambiental" e "poluição". Imagina-se que esse foi o intento da Convenção sobre a Proteção e Utilização de Cursos d'Água Transfronteiriços e Lagos Internacionais ao tratar seguidamente os últimos dois institutos no art. $1^{\circ}$ adiante descrito:

1. A expressão "águas transfronteiriças" designa todas as águas superficiais e subterrâneas que marcam as fronteiras entre dois ou mais Estados que as atravessam, ou que estão situadas nessas mesmas fronteiras; no caso de desaguarem no mar sem formarem um estuário, o limite dessas águas é uma linha recta traçada através da foz entre pontos na linha de baixa-mar das suas margens;

2) A expressão "impactos transfronteiriços" designa todo e qualquer efeito adverso significativo sobre o 
ambiente que resulte de uma alteração no estado das águas transfronteiriças, causada pela actividade humana cuja origem física se situe total ou parcialmente na área sob jurisdição de uma das Partes, sobre uma área sob jurisdição da outra Parte. Este efeito sobre o ambiente pode tomar várias formas: efeitos negativos sobre a saúde e a segurança do homem, a flora, a fauna, o solo, o ar, a água, o clima, a paisagem e os monumentos históricos ou outras infra-estruturas, ou interacção de alguns desses factores; pode também tratar-se de um atentado ao património cultural ou às condições sócio-económicas que resultem de modificações desses factores.

Soares destaca o caráter pioneiro desta convenção ao regular, pela primeira vez, normas gerais sobre Direito Fluvial Internacional, embora em âmbito regional (SOARES, 2001, p. 248). Trata-se de convenção aprovada por países membros da Comissão Econômica para a Europa (CEE), em 1992, na cidade de Helsinque, cujos conceitos consagrados interessam ao tema proposto.

Além da Convenção de Helsinque existe a Convenção das Nações Unidas sobre o Direito do Mar (Montego Bay, 10/12/1982). Cuida-se de vasto e complexo regramento do soft law que disciplina desde a delimitação dos espaços marítimos até a conservação dos recursos vivos e minerais inseridos neste espaço, bem como a prevenção direta da poluição transfronteiriça. $\mathrm{O}$ extenso conteúdo normativo justifica-se pelo seu aspecto de generalidade que permite que outras convenções possam dispor sobre a proteção do meio marinho, desde que compatíveis com os princípios e objetivos gerais dispostos na Convenção de Montego Bay (art. 237).

A responsabilidade civil internacional é regulamentada por duas espécies do instituto distintas e amplamente difundidas no Brasil: de um lado, responsabilidade subjetiva; do outro, a objetiva. 
No sistema tradicional da responsabilidade subjetiva internacional (ou por culpa), inexistem normas escritas especiais sobre sua regulamentação, cuja hermenêutica fica sob o crivo das fontes do Direito Internacional, tais como os costumes internacionais, as regras da jurisprudência de tribunais e de árbitros, os princípios gerais de direito e a doutrina, matéria essa que será melhor analisada no item seguinte. Aqui o dever de reparar, considerada obrigação secundária, surge a partir do cometimento de um ato ilícito, fonte primária para consecução do direito reivindicado. O ilícito faz-se por ato comissivo ou omissivo, atribuído pelo Estado, mesmo que não seja o agente direto do ato, devendo restar provada a vontade culposa no mesmo ato (aspecto subjetivo da ação).

Já no sistema da responsabilidade objetiva internacional (ou por risco), a obrigação de reparar emerge independentemente de qualquer análise em relação à licitude dos atos praticados pelos agentes. Por serem reguladas por normas escritas e precisas o espectro desta responsabilidade é limitado à hipóteses jurídicas específicas. Tendo em vista a despreocupação com a licitude do ato, a simples transgressão dos dispositivos legais acarreta a automática responsabilização dos infratores, uma vez que o elemento culpa encontra-se substituído pelo conhecido risco pela atividade exercida. Por isso comumente conhecida como normas de "responsabilidade internacional dos Estados por danos causados por atos não proibidos pelo Direito internacional".

Soares (2001, p. 214-215) ressalta que o conceito de poluição transfronteiriça é um tema recente quando observado não sob o foco do fenômeno da extraterritorialidade, mas pelo seu viés de anonimato. Para o Direito Internacional aplicar a responsabilidade sobre agentes desconhecidos, mas cujos danos são de escala internacional constitui matéria pouco ainda debatida.

Importante definição vem expressa na Convenção de Genebra sobre Poluições Atmosféricas Transfronteiriças 
de Longa Distância, concluída em 1979, de onde se extrai o conceito da expressão que deu nome a esta convenção. Significa a poluição atmosférica cuja fonte física se situa total ou parcialmente numa zona submetida à jurisdição nacional de um Estado e que produz efeitos danosos numa zona submetida à jurisdição de outro Estado, numa distância tal que geralmente não é possível distinguir as contribuições de fontes individuais ou de grupos de fontes de emissão (art. $1^{\circ}$, alínea b).

Estabelecidas breves digressões sobre a responsabilidade ambiental internacional segue a análise dos mecanismos jurídicos aplicáveis ao instituto.

\subsection{Mecanismos jurídicos de proteção ambiental na responsabilidade transfronteiriça.}

Como retratado no item 2.1 não se pode conceber os instrumentos da responsabilidade transfronteiriça ambiental sem se atentar para os preceitos de Direito Internacional. Desse modo importa discriminar as fontes jurídicas, de acordo com o Estatuto da Corte Internacional de Justiça (CIJ), estabelecida pela Carta das Nações Unidas como o órgão judicial internacional principal:

Art. 38, do Estatuto da Corte Internacional de Justiça (CIJ):

1. A Corte, cuja função é decidir de acordo com o direito internacional as controvérsias que lhe forem submetidas, aplicará:

a) as convenções internacionais, quer gerais, quer especiais, que estabeleçam regras expressamente reconhecidas pelos Estados litigantes;

b) o costume internacional, como prova de uma prática geral aceita como sendo o direito;

c) os princípios gerais de direito, reconhecidos pelas nações civilizadas; 
d) sob reserva da disposição do art. 59, as decisões judiciárias e a doutrina dos juristas mais qualificados das diferentes nações, como meio auxiliar para a determinação das regras de direito.

2. A presente disposição não prejudicará a faculdade da Corte de decidir uma questão ex aequo et bono, se as parte com isso concordarem.

Sem a intenção de prolongar o assunto interessa citar a ideia, difundida por parcela significativa da doutrina, a respeito do jus cogens. Tratam-se de normas de valor mais elevado em comparação a outros regulados por normas ordinárias, consagradas pela comunidade internacional. Como normas de caráter peremptório o jus cogens inadmitem a aplicação discricionária por parte dos Estados-membros, sendo vedada a alteração legislativa, ou mesmo a ignorância das regras, por outras senão aquelas de mesma natureza.

Em que pese a inclinação doutrinária o jus cogens não possui plena aceitação pela CDI. Segundo Soares (2001, p. 741) a Comissão ainda não se pronunciou expressamente sobre sua admissibilidade, embora admita indiretamente a vigência dos princípios manifestados na construção da responsabilidade criminal dos Estados. É o que se depreende da Convenção de Viena sobre Direito dos Tratados:

Artigo 53

Tratado em Conflito com uma Norma Imperativa de Direito Internacional Geral (jus cogens)

É nulo um tratado que, no momento de sua conclusão, conflite com uma norma imperativa de Direito Internacional geral. Para os fins da presente Convenção, uma norma imperativa de Direito Internacional geral é uma norma aceita e reconhecida pela comunidade internacional dos Estados como um todo, como norma da qual nenhuma derrogação é permitida e que só pode ser modificada por norma ulterior de Direito Internacional geral da mesma natureza. 
Sobre os mecanismos jurídicos propriamente ditos, dada a vastidão de legislações internacionais sobre os recursos hídricos, estes em suas variadas formas e pontos de vista, bem como a vigência das citadas normas em âmbitos regionais e internacionais variados, cumpre limitar o estudo somente em relação a importante Convenção de Helsinque, já mencionada no item 2.1.

$\mathrm{O}$ art. $3^{\circ}$ fornece valiosa recomendação atinente a prevenção, controle e redução do impacto transfronteiriço. Cabem aos países signatários desenvolver, adotar, aplicar e, sempre que possível, compatibilizar medidas jurídicas, administrativas, econômicas, financeiras e técnicas relevantes de modo a assegurar antecipadamente:

(a) o controle e a redução, quando não evitadas, da emissão de poluentes em sua fonte, valendo-se de tecnologias antipoluentes ou pouco poluentes;

(b) a criação de um sistema de licenciamento prévio que discipline as descargas de águas residuais sobre as águas transfronteiriças, devidamente autorizadas, e monitorizadas, a fim de proteger as águas transfronteiriças contra a poluição proveniente das fontes pontuais;

(c) o uso da melhor tecnologia aplicável às descargas de substâncias perigosas para aferição dos limites fixados para as descargas de águas residuais;

(d) a aplicação de medidas mais restritivas, inclusive a proibição de atividades quando a situação exigir;

(e) a aplicação mínima de tratamento biológico ou processos equivalentes às águas residuais urbanas, progressivamente;

(f) a tomada de medidas para reduzir as descargas de substâncias oriundas das indústrias e cidades por meio de tecnologia de ponta;

(g) o desenvolvimento e a implementação de práticas ambientais para redução de descargas poluidores provenientes 
de fontes difusas, em especial as decorrentes da agricultura;

(h) a avaliação de impacto ambiental e outros meios correlatos;

(i) a gestão sustentável dos recursos hídricos com abordagem ecossistêmica;

(j) a disponibilização real de planos de contingência;

(k) a tomada de medidas preventivas especificas contra a poluição das águas subterrâneas;

(l) a redução do risco de poluição acidental ao mínimo possivel.

Ao discenir sobre os tipos de responsabilidade civil internacional, Soares (2001, p. 716) revela que o sistema de responsabilidade objetiva é "particular e dirigido a determinados setores bem caracterizados". Daí porque se inadmite interpretação extensiva a outros casos que não se inserem na regulamentação específica.

Conquanto não seja o entendimento prevalente argumentamos a possibilidade de uso da dita interpretação extensiva em âmbito internacional quando relacionado aos interesses ambientais. Aliás, Soares não deixa transparecer seu posicionamento contrário ao recurso processual, mas apenas recita o entendimento atual.

A tese tem amparo no princípio da preservação ambiental, reforçada pelos princípios da precaução (Declaração Rio 92) e do equacionamento intergeracional (LEITE, 2002, p. 47). Trata-se de axiomas jurídicos internacionais, elevados a condição de jus cogens, em virtude do valor superestimado sobre o meio ambiente e sua preservação. Não se pode conceber a negação a tais meios interpretativos, ainda que as normas vigorem unicamente em regiões espaciais específicas sobre territórios de certos países.

Importante lembrar que se discute a interpretação extensiva de diplomas internacionais já consagrados, o que não se confunde com a utilização da analogia. Coelho (2009) ensina 
que esta "é uma técnica de decisão que consiste em transferir para um caso não regulado o mesmo padrão decisório de um caso já regulado a que o primeiro se assemelha em aspectos relevantes”. Interpretação extensiva, por sua vez, seria a ampliação do sentido da norma, de modo a enquadrar determinado caso não prescrito nesta. Vale dizer que na interpretação extensiva opera-se a subsunção do caso em concreto à letra fria dos dispositivos legais.

\section{O NEXO DE CAUSALIDADE NA ANÁLISE DA RESPONSABILIDADE DE PROTEÇÃO HÍDRICA TRANSFRONTEIRIÇA}

Apesar de reconhecido avanço da dogmática jurídica ambiental, sobretudo em relação à responsabilidade civil, perduram entraves que obstam a aferição de resultados verdadeiramente satisfatórios. Um dos gargalos está justamente na dificuldade/impossibilidade de comprovar o dano ambiental por inexistência, obscuridade ou inexatidão do nexo de causalidade que vincule a atividade exercida à lesão provocada.

\subsection{Análise dicotômica do nexo de causalidade na responsabilidade ambiental internacional}

Assim como no ordenamento brasileiro (salvo a esfera ambiental), o dever reparatório é regulado, de maneira ordinária, pelo sistema da responsabilidade subjetiva internacional (regra geral), sendo a responsabilidade objetiva a exceção. Em ambas as situações permanecem a incumbência processual universal de comprovar o famigerado nexo causal.

Soares (2001, p. 752) aponta a situação deplorável pela qual a parte lesada, como pessoa de direito privado, submete-se quando inserida no sistema da responsabilidade internacional subjetiva dos Estados: "se for a causadora do dano, a responsabilidade é atribuída ao Estado; se for vítima, deve contar com a 
boa vontade de seu Estado em assumir a defesa de seus direitos, por via da proteção diplomática".

Ante as "dificuldades" de demonstração do nexo causal compete propor a inversão do ônus probandi como medida mitigadora à inefetividade do instituto civil e à realidade jurídico-ambiental. Cuida-se de prerrogativa conhecida entre os processualistas, que vem sendo debatida entre os jurisconsultos do Brasil e que merece especial atenção pelo Direito Internacional Ambiental.

Cruz $(1998$, p. 32) traz a lume perspicaz indagação pertinente à famigerada causalidade na responsabilidade civil ambiental. Explica a autora que a dificuldade não procede exatamente da visualização do liame fático, mas se trata antes de um problema de prova. A autora ilustra seu posicionamento com dois casos práticos: os CFCs (Cloro Flúor Carboneto), causadores do buraco de ozônio e a poluição acidental de certo curso d'água.

No primeiro exemplo a "causação" até se encontra estabelecida, muito embora esteja "difusa". Tal fato leva a irresponsabilização, haja vista não poder identificar os agentes pelo evento danoso. Já no segundo exemplo, constatada que a poluição hídrica advém do despejo de produtos por várias indústrias ribeirinhas, a irresponsabilidade decorre da complexa tarefa em identificar quais fábricas contribuíram efetivamente com a contaminação fluvial.

A inversão de papéis sugerida converge com o princípio da prevenção/precaução referido no item 1.3.1, tendo em vista que tal hipótese é a materialização deste princípio, visualizada em campo processual. Supõe-se a substituição do critério da certeza processual pelo da existência de dano possível, em respeito à preservação do meio ambiente às gerações presentes e futuras (princípio da equidade intergeracional). Ao poluidor é reservada a tarefa de provar que a atividade executada não produz riscos (poluição em potencial) que ameace o bem ecológico equilibrado. 
Como enfatiza Milaré, "[...] a incerteza científica milita em favor do meio ambiente, carregando-se ao interessado o ônus de provar que as intervenções pretendidas não trarão consequências indesejadas ao meio considerado." (2000, p. 61-62). Nesse sentido, o princípio da precaução consagra o critério da probabilidade na tomada de decisões que envolvam a questão ambiental, em detrimento do critério da certeza. Ou seja, enquanto que ao demandado incumbe o dever de demonstrar, efetivamente, que a atividade desenvolvida não é lesiva ao meio ambiente, exigindo-se, portanto, certeza absoluta da inofensividade de sua prática, ao demandante cabe demonstrar que há probabilidade da ocorrência do dano (MIRRA, 2000).

De forma assemelhada a encontrada na lei consumerista nacional, a inversão probatória ambiental exige o cumprimento de dois requisitos: (a) verossimilhança, entendida como indícios plausíveis de que possa efetivamente ocorrer a lesão do bem ambiental e; (b) hipossuficiência, qualidade de inferioridade da parte autora em comparação ao agente, desnível manifestado sob o viés econômico, técnico (ou de informação) e/ou jurídico.

Os benefícios advindos da mudança de paradigma processual são de duas ordens: (a) imediata, pois o bem tutelado tendo a permanecer íntegro; (b) mediato, considerando a necessidade de o setor produtivo proceder sua auto (re)organização.

Quanto à segunda benesse deduz-se que as empresas deverão empreender esforços na execução de medidas não poluentes pelo intuito de angariarem maior percentual de lucro, em consonância com fins socioambientais. Isso porque a possibilidade de inversão acarretaria maior rigor pelas normas casuísticas internacionais, como se supõe acontecer. Por corolário empresa nenhuma arriscaria explorar atividade, vedada por prescrição legal, em favor de lucratividade duvidosa. Do mesmo modo presume-se haver o aumento pelo desestímulo à execução de tais atividades, também vedadas, tendo em vista a incidência do princípio da precaução sobre espaços do Direito e não somente circunscrito à orla de atuação dos tribunais. 
De certa forma, a inversão do ônus probandi exigirá, do corpo empresarial, uma remodelação estrutural, cujo maior beneficiária é a sociedade, inclusa aí as futuras gerações.

\subsection{O nexo de causalidade e a proteção hídrica transfronteiriça}

Alguns textos internacionais têm enfatizado a problemática do nexo causal inerente à perspectiva reparatória ambiental, embora de maneira tímida e dispersiva. Apesar de evidentes avanços encontrados no Direito Comparado, muito pouco se legiferou em escala internacional, mormente em relação à proteção hídrica transfronteiriça.

Merece destaque a Convenção sobre a Responsabilidade Civil por Danos Resultantes de Atividades Perigosas para o Meio Ambiente (Lugano, 21/06/1993). Conquanto não alinhave matéria correlata às águas transfronteiriças, tal norma inaugura a concepção probabilística na aferição do dever de reparar em substituição ao critério da certeza do dano ou do risco. Daí a sua importância ao tema proposto.

Determina o art. 10: "Quando é apreciada a prova do liame de causalidade entre o acontecimento e o dano ou, no quadro de uma atividade perigosa [...] entre a atividade e o dano, o juiz terá devidamente em conta o risco aumentado de provocar dano inerente à atividade perigosa." (MACHADO, 2004, p. 336-337). De fato não se tem conhecimento de normativa internacional que recomende, dentro do alcance do soft law, a inversão do ônus da prova. Contudo, a mudança do critério da responsabilização dá sinais de desenvolvimento do instituto em sua tríplice função de prevenir, reparar e punir.

Diante de um mundo contemporâneo de incertezas (Beck, 2010), o critério do provável ganha relevo em outras áreas do conhecimento, inclusive entre aquelas inseridas no campo das ciências exatas, tais como a matemática e física. O papel deci- 
sivo da probabilidade é afastar a noção de certeza absoluta e suplantar pelo juízo do provável.

Segundo Branco (1999, p. 42) "a certeza de um efeito parece ser meramente probabilística." O autor cita o curioso exemplo do calor ao gerar a ebulição da água. Tem-se a certeza prévia de que a água contida em um recipiente, ao ser aquecida uniformemente (por causa das correntes de convecção), entrará em ebulição no momento que atingir $100^{\circ} \mathrm{C}$ aproximadamente, conforme o nível de pressão. Não obstante descarta-se prematuramente a hipótese de moléculas frias separarem-se das quentes e formarem blocos de gelo no interior do volume líquido. A tese realmente existe, embora as chances de ocorrência sejam remotas. Para nosso raciocínio é conveniente que tais considerações sejam excluídas, de modo a restar somente a "certeza" do resultado de probabilidade maior, qual seja, a ebulição apenas do líquido.

De acordo com esse autor, "a natureza probabilística da certeza fica tanto mais evidente quanto mais distante estiver a causa do seu efeito final, como acontece nos sistemas complexos". E essa lógica passa a ter sentido no Direito Ambiental, tendo em vista a clara distância entre a causa e efeito do dano ambiental. $\mathrm{O}$ esforço da comunidade jurídica na construção de novas teorias para reduzir a complexidade da responsabilidade civil ambiental apoia-se justamente na tarefa de encontrar mecanismos que superem o paradoxo causal.

Podemos dizer que a Proposta Diretiva 91/219/COM, de maneira indireta, inverte o ônus probandi, pelo que se depreende da leitura do artigo transcrito: "art. 4.6: o demandante deverá provar o dano ou os prejuízos causados ao meio ambiente e estabelecer a existência de uma considerável probabilidade de presença de nexo causal entre os resíduos do produtor e o dano sofrido". Percebe-se que sobre o produtor recai a obrigação de apresentar a certeza pela inofensividade da atividade, enquanto ao demandante cabe apenas a demonstração da probabilidade do liame entre o dano e a atividade. 
Há também a Convenção para a Proteção do Meio Marinho do Mar Báltico de 1992, citada por Machado (2004, p. 337), que, em conluio à Convenção para a Proteção do Meio Marinho do Atlântico Nordeste, de 1992, torna dispensável a preexistência do nexo causal:

Art. $3^{\circ}$ As partes contratantes aplicam o princípio da precaução, que consiste em tomar medidas preventivas desde quando há fundamento para pensar que as substâncias ou a energia introduzidas, direta ou indiretamente, no meio marinho podem colocar em perigo a saúde humana, prejudicar os recursos biológicos e os ecossistemas marinhos, acarretar danos às qualidades de sítios ou dificultar outras utilizações legítimas do mar, mesmo quando a relação de causalidade entre as causas e os efeitos não estejam estabelecidas (fonte original: Recueil International de Législation Sanitaire, Genebra, Organisation Modiale de La Santé, v. 44, n. 1, 1993, traduzida pelo autor).

Canotilho (1998, p. 49) indica a necessidade de transferir o ônus da prova para os potenciais poluidores, justificada também pelo princípio da precaução, nos casos em que: a) inexistem constatações de danos imediatos e concretos pelo desconhecimento científico, muito embora perdure a expectativa de eventual mal a ser causado; b) verificam efetivamente a ocorrência de danos, embora impunes ante a mesma ignorância científica acerca das causas que o provocaram; c) do mesmo modo que a alínea $b$, não se conhece cientificamente o nexo de causalidade entre causa hipotética e os danos verificados.

Tendo em conta a essencialidade da temática da proteção hídrica sobre o Direito Ambiental admite-se que o obstáculo nexo de causalidade foi pouco retratado pelas convenções e tratados internacionais, em prejuízo à efetividade da responsabilidade ambiental. 


\section{CONCLUSÃO}

Sobre o tema da crise atual que vem enfrentando as economias mundiais, não se pode olvidar a relevante influência que a variável meio ambiente tem surtido. Todavia as grandes potências têm insistido em ignorar as evidências, de forma a priorizar o estudo de variáveis outras atinentes à economia, assunto principal na pauta das nações. Se for certo que a superpopulação mundial e o aumento exacerbado do consumo, fruto do modelo capitalista constitui a primeira evidência, as causas da crise, por outro lado insere-se o problema da escassez dos recursos naturais, cuja análise faz-se de forma escamoteada. Seja o petróleo, a água ou os minérios essenciais à produção industrial é certo que o esgotamento das fontes tem gerado o quebra-quebra das principais potências, entre elas os EUA e a União Europeia. Sabe-se que um dos fatores que fez eclodir a hegemonia americana está na riqueza de recursos naturais de outrora. De uns anos atrás para cá a produção petrolifera apontou sinais de fadiga. Sendo ainda considerado o principal instrumento à produção industrial, sua falta em níveis exigidos pela economia atual tem provocado mudanças cada vez mais repentinas dos polos de investimento e, por conseguinte, especulação no mercado acionário. Sem pretender aprofundar o assunto em termos técnicos próprios da economia, o fato é que a escassez dos recursos naturais representa hoje, mormente, um dos principais ou, quiçá, o principal vetor da economia. Daí a importância dos estudos do ambiente, sobretudo do Direito Ambiental, para mensurar coerentemente a influência da ecologia nos assuntos relacionados à Economia, de modo a inaugurar o novo padrão de produção industrial sob o foco da integridade ecológica.

O dano ambiental comporta peculiaridades próprias, de ordem subjetiva, objetiva, temporal e científica, que impedem a plenitude indenizatória pelos moldes tradicionais. Por outro viso, mesmo diante da consagrada teoria do risco integral, ajustável à realidade ambiental, inexiste uma resposta satisfatória 
em relação ao fim precípuo da reparação. A teoria do risco integral está diretamente relacionada com a teoria da conditio sine qua non, pela qual havendo a pluralidade de causas, todas serão consideradas eficientes para produção do dano. A dificuldade reside no fato de que ainda perdura a obrigação da parte lesada concatenar os danos provocados (consequência) com a atividade exercida (causa), razão esta que restringe a o alcance do princípio alterum non laedere.

Nota-se que o Direito Internacional Ambiental possui sérias dificuldades em consagrar a responsabilidade objetiva internacional (ou responsabilidade internacional dos Estados por danos causados por atos não proibidos), sendo a soberania dos Estados um dos principais entraves. As normas para regulamentar estas questões, embora tenham certo efeito moral sobre os Estados considerados entes soberanos, não produzem normas coercitivas capazes de obrigar esses na reparação do dano, uma vez que se baseiam no princípio da cooperação internacional, em que só se pode dar entre dois Estados considerados Partes da Convenção. No que tange a proteção hídrica por poluição transfronteiriça a regulamentação é ínfima.

A atenuação do nexo da causalidade, a partir da Teoria da Probabilidades, inseridas no contexto da Sociedade de Risco, explicada originalmente por Beck, parece representar medida proativa à efetividade do instituto da responsabilidade civil. Exemplo promissor da inserção do risco como elemento fundante da responsabilidade ambiental internacional é a Convenção de Lugano. Daí a necessidade de utilizar seus dispositivos, em especial aqueles referentes ao abrandamento do nexo causal, à realidade da responsabilidade por poluição transfronteiriça dos recursos hídricos.

A passos lentos observa-se a tendência de romper com o sistema tradicional de responsabilidade subjetiva internacional, em nome da preservação ambiental para as presentes e futuras gerações, construído sobre a noção absoluta da soberania dos Estados, com a substituição pelo modelo de responsabilização 
objetiva, guiado pelo princípio da cooperação. Estão contemplados não apenas as hipóteses específicas expressas em atos não proibidos, mas também eventos danosos oriundas do próprio exercício das atividades lícitas.

Nesse contexto o sistema ancorado agora sobre a probabilidade dos fatos, em contraposição a certeza e previsão dos riscos dão amparo à defesa pela inversão do ônus da prova do nexo causal em favor do lesado demandante. A este não se desvencilha a obrigação de demonstrar o liame entre o dano (ou sua iminência) e a atividade exercida, embora baste apenas a verossimilhança das alegações.

\begin{abstract}
The worrying shortage of drinking water, combined with the constant cross-border pollution of water resources has caused fervent debate among the world's authorities. Among the topics we discuss the accountability of states and individuals in the pollution of water assets. From the perspective of the current risk society we live in, the theory devised by Ulrich Beck, we propose a new way of looking at international liability for transboundary water pollution: the reversal of the duty to prove causation, the entrepreneur must demonstrate that activity exerted not involve any risks or environmental damage and future.
\end{abstract}

Keywords: Liability border. Venture company. Causation

\title{
REFERÊNCIAS
}

ARAGÃO, Maria Alexandre de Sousa. O princípio do poluidor-pagador: pedra angular da política comunitária do ambiente. Coimbra: Coimbra Editora, 1997.

ANTUNES, Paulo de Bessa. Dano ambiental: uma abordagem conceitual. Rio de Janeiro: Lumen Juris, 2000. 
AYALA, Patryck de Araújo; LEITE, José Rubens Morato. Direito ambiental na sociedade de risco. Rio de Janeiro: Forense Universitária, 2002.

BECK, Ulrich. Sociedade de Risco: rumo a uma outra modernidade. Tradução de Sebastião Nascimento. São Paulo: Editora 34. 2010.

BENJAMIN, Antônio Herman. O princípio poluidor-pagador. In: BENJAMIN (Coordenador). Dano Ambiental - Prevenção, Reparação e Repressão. São Paulo: Revista dos Tribunais, 1993.

Responsabilidade civil pelo dano ambiental. Revista de direito ambiental. São Paulo: Revista dos Tribunais, v. 9, p. 4-52, jan./mar. 1998.

CANOTILHO, José Joaquim Gomes (coord.). Introdução ao direito do ambiente. Lisboa: Universidade Aberta, 1998.

COELHO, André. Analogia e Interpretação extensiva. Disponível em: $<$ http://aquitemfilosofiasim.blogspot.com.br/2009/11/analogia-einterpretacao-extensiva.html>. Acesso: 11 abr. 2012.

CRUZ, Branca Martins da. Responsabilidade civil pelo dano ecológico: alguns problemas. Revista de direito ambiental. São Paulo: Revista dos Tribunais. v. 5, p. 4-41, jan-mar. 1998.

CUSTÓDIO, Helita Barreira. Responsabilidade civil por danos ao meio ambiente. São Paulo: Millenium, 2006.

DIAS, José de Aguiar. Da responsabilidade civil. 11. ed. rev., atual. e aum. por Rui Berford Dias. Rio de Janeiro: Renovar, 2006.

DI GIORGI, Raffaele. O risco na sociedade contemporânea. In:

Revista Sequência. Revista do Curso de Pós-Graduação em Direito da Universidade Federal de Santa Catarina, jun. 1994, n. 28, ano 15.

DINIZ, Maria Helena. Curso de direito civil brasileiro: responsabilidade civil. 18. ed. rev., atual. São Paulo: Saraiva, 2003. v. 7.

FERREIRA, Aurélio Buarque de Holanda; FERREIRA, Marina Baird; SILVEIRA, Alzira Malaquias da (Coord.). Novo dicionário Aurélio da língua portuguesa. 3. ed., rev. e atual. Curitiba: Positivo, 2004.

FIORILlO, Celso Antonio Pacheco. Curso de direito ambiental brasileiro. 10. ed., rev., atual. e ampl. São Paulo: Saraiva, 2009. 
FRANCO, Paulo Sérgio de Moura; DALBOSCO, Ana Paula. A tutela do meio ambiente e responsabilidade civil ambiental. Jus Navigandi, Teresina, ano 6, n. 52, nov. 2001. Disponível em: <http://jus2.uol.com.br/doutrina/ texto.asp?id=2357>. Acesso em: 20 ago. 2011

FREITAS, Vladimir Passos de. Direito administrativo e meio ambiente. 3. ed. Curitiba: Juruá, 2004.

. Poluição de águas. Disponivel em: <http://daleth.cjf.jus.br/ revista/numero3/artigo02.htm>. Acesso: 25 ago. 2011.

GONÇALVES, Carlos Roberto. Responsabilidade Civil. 8. ed. rev. São Paulo: Saraiva. 2003.

HUPFFER, Haide Maria; NAIME, Roberto. Catástrofes ambientais: irresponsabilidade organizada? Um olhar a partir de Ulrich Beck. Estado de Direito. Porto Alegre: Atlas, ano V, n. 29, p. 10-11. 2011.

LEITE, José Rubens Morato. Dano ambiental: do individual ao coletivo extrapatrimonial. 2. ed. rev., atual. e ampl. São Paulo: Revista dos Tribunais, 2003.

LIMA NETO, Francisco Vieira. Responsabilidade civil das empresas de engenharia genética. Leme: Editora do Direito, 1997

MACHADO, Paulo Affonso Leme. Direito ambiental brasileiro. São Paulo: Malheiros, ed. 18. 2010.

MARCHESAN, Ana Maria Moreira; STEIGLEDER, Annelise Monteiro. Fundamentos jurídicos para a inversão do ônus da prova nas ações civis públicas por danos ambientais. In: BENJAMIN, Antônio Herman (Org.). Anais do $6^{\circ}$ Congresso Internacional de Direito Ambiental. São Paulo: IMESP, 2002.

MEIRELLES, Hely Lopes. Direito administrativo brasileiro. 29. ed. São Paulo: Malheiros, 2004.

MILARÉ, Édis. Direito do ambiente: a gestão ambiental em foco : doutrina, jurisprudência, glossário. 5. ed. reform., atual. e ampl. São Paulo: Revista dos Tribunais, 2007.

MIRABETE, Julio Fabbrini. Manual de direito penal: volume 1 - parte geral. 17. ed. rev., atual. São Paulo: Atlas, 2001.

MIRRA, Álvaro. In: MORATO LEITE, José Rubens (Org.). Inovações em 
Direito Ambiental. Florianópolis: Fundação Boiteux, 2000.

REBOUÇAS, Aldo da Cunha. Proteção dos recursos hídricos. In: Direito, água e vida (Org. Antonio Herman Benjamin). $7^{\circ}$ Congresso Internacional de Direito Ambiental. São Paulo: Imprensa Oficial. 2003. v. 1.

RODRIGUES, Silvia Macedo. Síntese histórica da legislação ambiental brasileira. (1500 a 2006). Blog Direito Ambiental: <http:// dirambientalexlege.blogspot.com/2010/03/sintese-historica-da-legislacao. html>. Acesso em: 25 ago. 2011.

SANTA CATARINA. Tribunal de Justiça. Relator: Desembargador Newton Trisotto. Acórdão em apelação cível n. 2008.006521-3. Autores: Cezar Roberto Netto Piazza, Maria Alice da Rocha Piazza e Diego da Rocha Piazza. Réu: Estado de Santa Catarina. Data da publicação: 10/02/2009.

SANTOS, Boaventura de Sousa. Por uma concepção multicultural de direitos humanos. Revista crítica de ciências sociais. Coimbra, n. 48, p. 11-32, jun. 1997.

SILVA, Danny Monteiro da. Dano ambiental e sua reparação. Curitiba: Juruá, 2006.

SILVA, José Afonso da. Direito Ambiental Constitucional. 9. ed.São Paulo: Malheiros, 2001.

SOARES, Guido Fernando Silva. Direito Internacional do Meio

Ambiente: emergência, obrigações e responsabilidade. São Paulo: Atlas, 2001.

STOCO, Rui. Tratado de responsabilidade civil. 6. ed. rev., atual. e ampl. São Paulo: Revista dos Tribunais, 2004. 